\title{
SERIALIZATION AND VERIFICATION OF MEDICINAL PRODUCTS - A PILOT STUDY AMONG PHARMACISTS IN BULGARIA
}

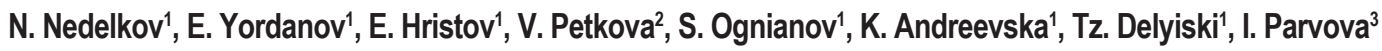 \\ ${ }^{1}$ Faculty of Chemistry and Pharmacy, Sofia University "Sv. Kliment Ohridski" - Sofia, Bulgaria \\ ${ }^{2}$ Faculty of Pharmacy, Medical University - Sofia, Bulgaria \\ ${ }^{3}$ Clinic of Rheumatology, Department of Internal Medicine, Medical University - Sofia, Bulgaria
}

\begin{abstract}
Background. In an attempt to stop the distribution of falsified medicinal products, the EU has adopted Directive 2011/62/EU. Since 9th February 2019, each package of medicinal product must be given a unique number in combination with a mandatory indicator of integrity. The Directive requires the creation of a system of serialization and verification of the medicinal products. Aim of the study: To determine the level of awareness about the serialization and verification system among masters of pharmacy and the preparedness of Bulgarian pharmacies to meet the new challenges. Materials and methods: $A$ pilot survey was conducted in 25 pharmacies in Sofia. 41 specialists in pharmacy holding a master degree were interviewed using the "direct individual survey" method. Results and discussion: The knowledge about the availability of new regulatory requirements is in serious dissonance with the established high level of non-awareness of the forthcoming initiatives. Over $2 / 3(78 \%)$ of the respondents do not know what the practical challenges to their pharmacy practices will be.
\end{abstract}

Key words: falsified medicinal products, safety features, verification, serialization

Corresponding author: Associate Professor Emil Hristov, MD, PhD Faculty of Chemistry and Pharmacy, Sofia University "Sv. Kliment Ohridski", 1 James Bourchier Blvd., 1164 Sofia, Bulgaria, tel. +359 899866 124, e-mail: hristovemil@mail.bg

\section{INTRODUCTION}

T he issue of the entry of falsified medicinal products into the market was first raised for discussion at the international level in 1985 at the Conference of experts on the rational drug use organized by the World Health Organization (WHO) in Nairobi, Kenya [1, 2]. The final document adopted by the Conference recommended that WHO, together with the international institutions, national competent authorities and non-governmental organizations, should start detailed investigations of the problem of counterfeit medicines, and inform the governments of the Member States about the nature and extent of this problem [1, 2].

Until 2006, a number of international initiatives were held under the WHO auspices, ending with the IMPACT (International Medical Products Anti-counterfeiting Taskforce) initiative as a main tool and way of WHO to fight against the counterfeit medicines $[3,4]$. In the background of the WHO efforts, the EU and the Member States did not take any adequate measures, as it was assumed that the problem of the counterfeit medicines concerned mainly the third world countries. 
The processes of globalization in general, and the problem of falsified medicinal products could not miss the EU Member States, and since 2000, there have been numerous reports of counterfeit medicines entering the market in Europe $[5,6,7,8]$. This triggered the reaction of the European Parliament, which passed a special resolution on this issue and set the following tasks [9, 10]: The EU must take urgent measures to effectively combat the counterfeit medicines; The EU must take steps to strengthen the regulatory and quality control of the medicinal products (MP); The EU must play a key role in the creation of a system, which criminalizes the supply and distribution of counterfeit medicines, and take actions to change the legislation in each Member State; strengthen the cooperation at national and international level among the various competent authorities and take specific measures against the entry of counterfeit medicines; set up an action plan [11, 12].

The EU's scientific and regulatory understanding of the measures against the counterfeit medicines finds its practical implementation in Directive 2011/62/EU of the European Parliament and of the Council of 8 June 2011 amending Directive 2001/83/EC on the Community code relating to medicinal products for human use, as regards the prevention of the entry into the legal supply chain of falsified medicinal products [13].

The Directive introduces a uniform definition of "falsified medicinal product" for all Member States and redefines the terms "active substance" and "excipient" (auxiliary substance). Natural persons or legal entities, which supply, hold, store, deliver or export medicinal products, may conduct such activities only if they meet the requirements for obtaining a wholesale authorization in accordance with Directive 2001/83/ $E C$, i.e. only if they are part of the "legal" channels of distribution. Strict measures are in place to put an end to the functioning of unlicensed vendors and the chain of intermediaries. The creation of a European database of wholesalers of medicinal products is proposed. Control and inspection measures are strengthened - harmonized principles and guidelines for conducting inspections of wholesalers are being set up. Stricter rules of control and inspection of manufacturers of active substances are introduced. A notification regime is introduced. Provisions of Good Manufacturing Practice in manufacturing of excipients are set out. The Directive requires the Member States to exercise strict controls on import and export of medicinal products through the free customs zones. Indication and labeling of safety features for prescribed medicinal products is introduced.

Regulation (EU) No. 2016/161 of the European Commission lays down detailed rules for the safety features appearing on the packaging of medicinal prod- ucts for human use [14]. A track and trace system in the sale of medicines is being implemented. The project introduced a unique number on the packaging of medicinal products in combination with a mandatory identifier of the packaging integrity until 9 February 2019. The two markers should indicate that the packaging is unique and its content, blisters and/or ampoules have not been replaced. The new regulations cover mainly prescription medicines. New processes and parameters are introduced into the distribution system: verification - identification and check of the authenticity of the medicinal products; deactivation of the unique identifier; serialization - unique code on each packaging of medicinal products; safety features of the medicinal products - unique identification code and evidence against package tampering.

Safety features consist of two elements placed on the packaging of each medicinal products: 1) individual identification number (unique identifier GTIN (general identification number)) and a unique sequence in a two-dimensional barcode allowing the identification and authentication of the individual packaging on which it is printed, and 2) a device to verify whether the packaging of the medicinal product has been tampered (anti tampering device). The Directive and the Regulation require the implementation of a national medicines verification system in each EU member state that will store information on the individual identification number and will allow the inspection of each package given to a patient in the pharmacy. The national systems will be linked to a unified pan-European medicines verification system and will work in synergy. The overall logic of the Directive is based on the voluntary principle - in other words, Marketing Authorization Holders and manufacturers want such self-regulation and the EU authorities give them the opportunity to create, implement and operate the self-regulation to protect themselves from the counterfeiting of their own medicines. For this reason, the organizations responsible for medicines verification are incorporated as non-profit associations by understanding. The expected end-result is reduction of the manufacturers' losses and greater safety for the end users - patients. The Bulgarian Medicines Verification Organization was registered on 20 April 2016 and is the second such organization created in the EU.

The main principles of the verification and serialization system are:

- each manufacturer must place a special marking device and software on its conveyor lines, thus generating unique codes. The unique code is entered into the European system at the manufacturing stage.

- once launched to the market, the package of the medicinal product will go through various distribution 
units with this number. The code will not be marked at the wholesaler, if it is obtained directly from the manufacturer, as this is an authorized distribution channel.

- when the medicine arrives at the pharmacy, the pharmacist will check if this is the legal

package at the entry level. Each pharmacy must have a scanner with a 2D barcode reader. When a pharmacist releases the drug to a patient, he must immediately write it off the system. Investments by the manufacturers are expected to be the biggest. It is considered that the completion of the conveyor lines with serial number generating devices and software solutions will cost about EUR 200-300 thousand per conveyor line. Pharmacies must be equipped with a barcode reader - there are no preliminary data on the amount of the investment. It is expected that these investments will not directly affect the ultimate drug prices. Reduction of the losses suffered by the manufacturers due to counterfeit medicines is expected to offset these investments.

Effective as of 9th February 2019, pharmacies will not be able to release prescription medicines without conducting verification. They will be able to sell all products, which do not require prescription - over-the-counter drugs (OTC), nutritional supplements, medical devices, cosmetics, which can remain in drugstore mode. An interesting question that arises is whether Bulgarian pharmacies are ready to face the new challenges.

\section{OBJECTIVES}

The aim of this study is to determine the level of awareness and knowledge of masters of pharmacy about the new EU legislation, the creation and functioning of the medicines serialization and verification system, and the preparedness of Bulgarian pharmacies to face the new challenges. The purpose of the study is to display the trends.

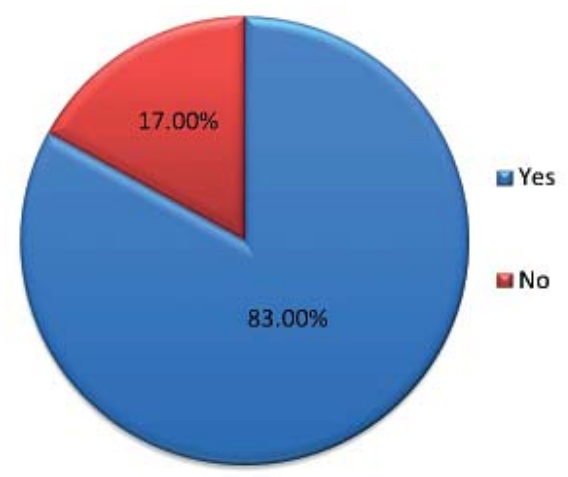

Fig. 1. Question No. 1. Are you aware of the existence of a Directive regarding the prevention of the entry of falsified medicinal products into the legal supply chain?

\section{MATERIALS AND METHODS}

A pilot study in 25 (2.28\% from total number) [15] pharmacies in the region of Sofia, Bulgaria was conducted. Time of study: January-February 2018 - one year before the practical implementation of the serialization and verification process. A questionnaire containing 8 questions -7 closed and 1 open type was designed. The data collection was done using the "direct individual poll" method. The target group included 41 Masters of Pharmacy (1.90\% from total number) [15] - 15 of them being pharmacy managers and 26 pharmacists working under one employment contract.

\section{Statistical analysis}

A descriptive statistical analysis of the results of the surveys was performed. The data were processed with the SPSS software product.

The responses were tested with various additional statistical methods, such as completeness of data, consistency of responses, internal item consistency, discriminant validity. The convergence and divergence factor of the responses was calculated and a degree of reliability of the obtained answers at normal values set for this indicator from 0.00 to 0.40 with the confidence level $p<0.05$ was determined. The homogeneity of the results was assessed using inter-rater techniques: various people, the same test was assessed. The reliability was measured by the Chronbach' alpha (Rtt) factor with normal values $\geq 0.70$ and average interitem correlation (Rii) with normal range 0.15-0.50.

\section{RESULTS}

The results are presented in Figs. 1 to 8 .

A very high level of inconsistency of the responses and a lack of internal consistency between them were discovered. The results go beyond the boundaries set for the Chronbach' alpha factor and average inter-item correla-

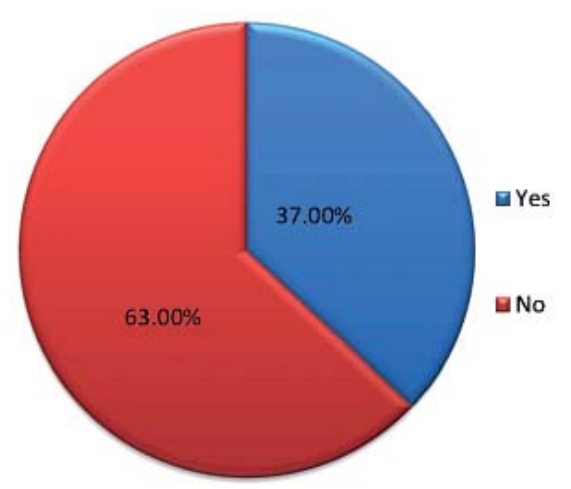

Fig. 2. Question No. 2. Are you aware of the existence of a Regulation by the European Commission laying down detailed rules for the safety features on the packaging of medicinal products for human use? 


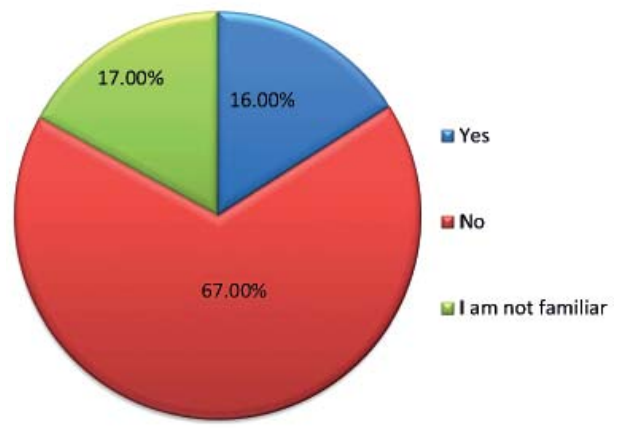

Fig. 3. Question No. 3 Are you aware of the existence of the Bulgarian Medicines Verification Organization (BMVO) and of its purpose?

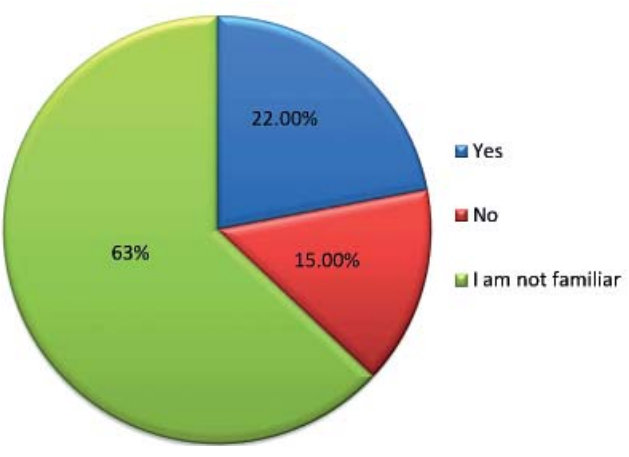

Fig. 4. Question No. 4. Do you know what exactly the term medicines verification and serialization processes means?

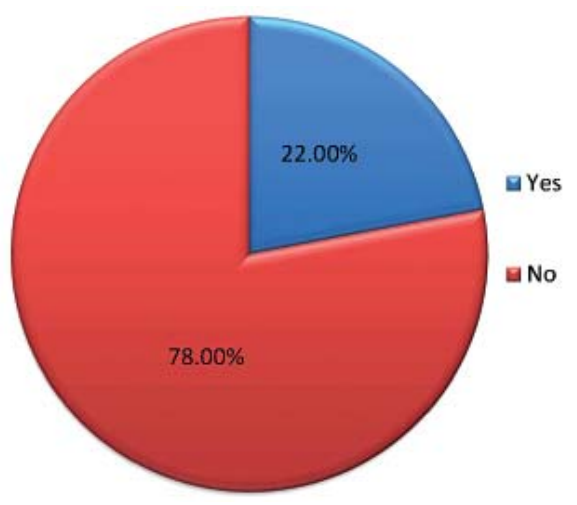

Fig. 5. Question No. 5. Do you know what impact the medicines verification system will have on your pharmacy practice, effective as of 09 February 2019?

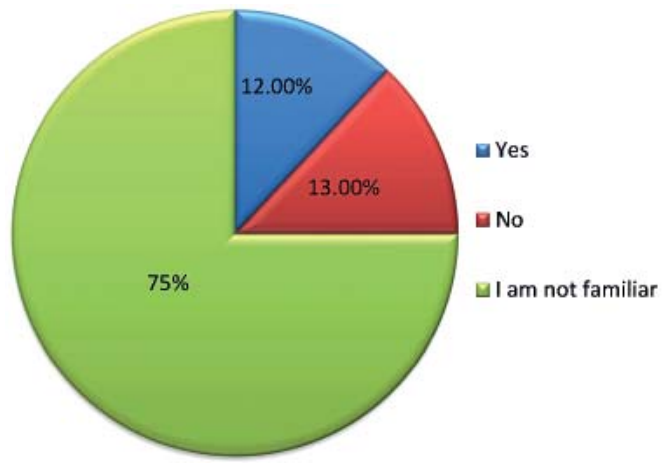

Fig. 6. Question No. 6. Will you be required to register with the medicines verification system?

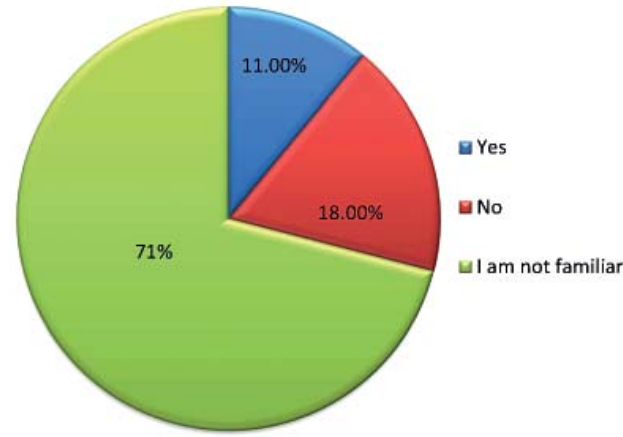

Fig. 7. Question No. 7. Do you have any information that you will be required to have a special software and other technical equipment?

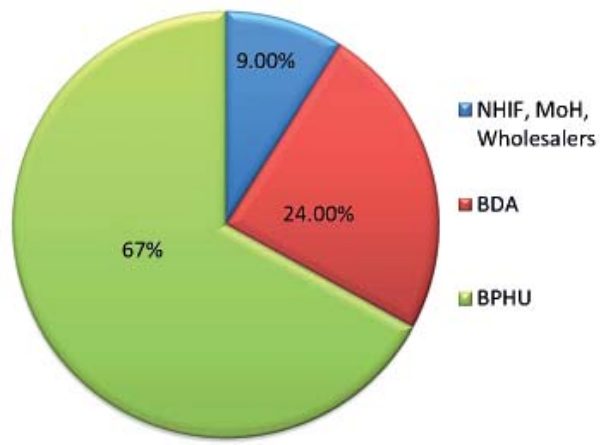

NHIF - National Health Insurance Fund; MoH - Ministry of Health; BDA Bulgarian Drug Agency; BPHU - Bulgarian Pharmaceutical Union

Fig. 8. Question No. 8. If you do not have the information required in respect of the questions of survey, who are you going to contact? (open question)

tions. On the other hand, there is a discriminant validity and reliable scales. For example: $83 \%$ of the respondents answered that they are not aware of the existence of a Directive regarding the prevention of the entry into the legal supply chain of falsified medicinal products, but only $63 \%$ are aware of the existence of a further Regulation of the European Commission laying down detailed rules for the safety features appearing on the packaging of medicinal products for human use, which further develops the Directive - there is $20 \%$ dissociation. The awareness of the existence of new regulatory requirements is in a serious dissonance with the very high level of the lack of information regarding the specificity of the forthcoming innovations. Over $2 / 3$ (78\%) of the respondents do not know what the practical challenges to their pharmacy practices will be. Over $2 / 3(71 \%)$ of the interviewed persons have no information whether they will need any new program products and decoding devices or whether there will be any changes in the NHIF servicing. They also do not know how prescription medicines will be released in the free market, what the OTC release will be and if they will be able to release single blisters, ampoules etc. The financial burden on the pharmacy practices, the need of hiring additional personnel etc. are unclear also. The Bulgarian Pharmaceutical Union appears to be the main source of information for the practicing pharmacists $(67 \%)$, and $24 \%$ of the interviewed persons will rely on the Bulgarian Drug Agency. 


\section{DISCUSSION}

As of $9^{\text {th }}$ February 2019, the supply chain for dispensing medicines to patients in Europe should become even safer. Prescription medicines are verified for the authenticity by the European Medicines Verification System (EMVS). This system (EMVS) is a world innovation. The financial impact on the subjects in the pharmaceutical sector - mainly pharmacies, and especially on the patients, is still not clear [16].

Bulgaria is one of the first countries to implement the new legislation. The Bulgarian medicine verification system, part of the unified European system, was ready for its official start on February 9, 2019 announced by the executive director of the Bulgarian medicines verification organization (BgMVO). The expectations were that this stress test for the medicines supply chain will eliminate $99 \%$ of all incorrect practices [17]. The real results are still in progress.

\section{CONCLUSION}

The introduction of verification and serialization of the medicinal products is a serious challenge to the entire pharmaceutical sector both in Bulgaria and the EU. This survey showed that the main disadvantages are the lack of sufficient information, unsatisfactory involvement of the governmental bodies and institutions in the conduct of drug policy in the serialization and verification processes etc. 7 years after the adoption of the Directive, two years after the adoption of the Regulation and few months after the serialization and verification system came into force, the level of knowledge of their practical dimension is very low. There are also some new unsuspected challenges: What will be the participation of the pricing and reimbursement authorities in these processes? To what extend the Ministry of Health will be involved in them? Will the government and institutional medicinal products control systems change and in what direction? How will the public institutions use the information accumulated in these systems? Who and how will analyze the accumulated information? To what extent and how will the information gathered in the European and national" information cloud" be used for the purposes of rational drug use, accountability, taxation etc.? There are numerous questions, which will be answered by the practice and give rise to further studies.

\section{REFERENCES}

1. Counterfeit medicines: a public health challenge. WHO. January 2010, http://www.who.int/news-room/fact-sheets/detail/ substandard-and-falsified-medical-products.

2. IMPACT International Medical Products Anti-counterfeiting Taskforce. The Handbook. Facts, Activities, Documents Developed by the Assembly and the Working Groups, 20062010 (2011; 164 pages) http://apps.who.int/medicinedocs/ en/m/abstract/Js20967en/.
3. International Medical Products Anti-counterfeiting Taskforce, Principles and Elements for National Legislation against Counterfeit Medical Products. Text endorsed by IMPACT General Meeting. Lisbon, 12 December 2007 http://apps. who.int/medicinedocs/documents/s20967en/s20967en.pdf.

4. Preliminary Draft Survey on national legislation on "Counterfeit medicines", Working document WHO/ACM/1, 4 may 2010. https://www.who.int/medicines/services/counterfeit/ WHO_ACM_Report.pdf.

5. Hristov El, Kulaksazova RJ. Bulgarian Drug Agency experience with counterfeit medicines. Oral report. 53 meeting of Heads of Medicine Agencies, Brdo, Slovenia, 13-14.04.2008.

6. Hristov El, Kulaksazova RJ. Counterfeit medicinal products -Introduction in theory and practice. Oral report. Pharmaceutical Fourth Symposium on Southeast Europe. EGA, Istanbul, Turkey, 2008.

7. Hristov EI, Spassova SS. Bulgaria tackles increasing numbers of counterfeit drugs. Pharmaceutical Dialogue. German Association of Pharmaceutical Parallel Distributors, 2010;12(4):4.

8. Hristov El, Dimitrova ZD, Parvova IA et al. Scientific, Regulatory and Practical Approaches to the Fight against Counterfeit Medicinal Products. Bul Exp J US-China Med Sci, 2016; (13):1-12.

9. Resolution on Counterfeiting Medicinal Products. European Parliament, September 2006. http://www.europarl.europa. eu/sides/getDoc.do?type=MOTION\&reference=B6-20060483\&language $=E N$.

10. European Parliament. (Brussels 14 May 2007), First European Parliamentary Symposium on Pharmaceuticals, Putting an End to Drug Counterfeiting. www.epp-ed.eu/Press/peve07/ docs/070514programme_pharmaceuticals_en\%20.pdf.

11. Summary of the Impact Assessment, Commission staff working document: Accompanying document to the Proposal for a Directive of the European Parliament and of the Council amending Directive 2001/83/EC as regards the prevention of the entry into the legal supply chain of medicinal products which are falsified in relation to their identity, history or source. SEC (2008) 2674, Brussels, 10 Dec 2008. https://eur-lex.europa.eu/legal-content/EN/TXT/?uri=celex\%3A52014SC0208,.

12. Impact Assessment, Commission staff working document: Accompanying document to the Proposal for a Directive of the European Parliament and of the Council amending Directive 2001/83/EC as regards the prevention of the entry into the legal supply chain of medicinal products which are falsified in relation to their identity, history or source. SEC (2008) 2674, Brussels, 10 Dec 2008. https://eur-lex.europa.eu/legalcontent/BG/TXT/?uri=CELEX:52016SC0410.

13. Directive 2011/62/EU of the European Parliament and of the Council of 8 June 2011 amending Directive 2001/83/EC on the Community code relating to medicinal products for human use, as regards the prevention of the entry into the legal supply chain of falsified medicinal products. https://eur-lex. europa.eu/legal-content/en/TXT/?uri=CELEX:32011L0062.

14. Commission delegated regulation (EU) 2016/161 of 2 October 2015 supplementing Directive 2001/83/EC of the European Parliament and of the Council by laying down detailed rules for the safety features appearing on the packaging of medicinal products for human use. https://eur-lex.europa.eu/ legal-content/EN/TXT/?uri=CELEX:32016R0161].

15. National register of BPhU, https://bphu.bg/19_РЕГИСТЪР/22_София-столична.htm?search:13.

16. Medicines verification system goes live across EU to better protect patients from falsified medicines, https://www.efpia.eu/ news-events/the-efpia-view/statements-press-releases/medicines-verification-system-goes-live-across-eu-to-better-protectpatients-from-falsified-medicines/.

17. Official start of Bulgarian medicines verification system, https:// www.bgmvo.org/en/single-new/51/.

Received: July 2019 - Accepted: July, 2019 